PUEBLOS ARCAICOS E HISPANIA ROMANA. SISTEMA DE CASTIGO Y CONTROL SOCIAL 
Rev. CAP Jurídica Central N. 4 - agosto 2019, ISSN 2550-6595

\title{
PUEBLOS ARCAICOS E HISPANIA ROMANA. SISTEMA DE CASTIGO Y CONTROL SOCIAL ${ }^{1}$
}

\author{
RAMiro J. GARCía FALCONÍ ${ }^{2}$ \\ UNIVERSIDAD CENTRAL DEL ECUADOR, QUITO - ECUADOR
}

\section{RESUMEN:}

La ocupación romana a la Península Ibérica, que inicia en el año 218 A.C. y dura hasta el siglo V, en que cae el Imperio Romano, no solo genera nuevas relaciones sociales y culturales, sino que afecta ámbitos como el Derecho y, por supuesto, la manifestación más violenta de éste, la penal. Si bien muchos de los conflictos se resolvían bajo los usos y costumbres ancestrales de los pueblos hispánicos, el Derecho romano tiene una impregnación importante, conforme lo demuestran las fuentes epigráficas que se conservan hasta el presente, tanto en lo penal, como en lo procesal.

1 Artículo entregado por el autor el 15 de marzo de 2019 y aprobado el 25 de junio de 2019

2 Catedrático de Derecho penal y Derecho procesal penal de la Universidad Central del Ecuador. orcid.org/0000-0002-6343-563X 
Rev. CAP Jurídica Central N. 4 - agosto 2019, ISSN 2550-6595

\section{PALABRAS CLAVE:}

Ocupación, fuentes epigráficas, Ius Gentium, deditium, Ley de Urso, actio noxalis.

\section{ABSTRACT:}

The Roman occupation of the Iberian Peninsula, which began in 218 B.C., and lasted until the fifth century when the Roman Empire fell, not only generated new social and cultural relations, but also affected areas, such as law and, of course, the more violent manifestation of it: criminal law. Although many of the conflicts were resolved under the ancestral customs and habits of the Hispanic people, Roman law has an important influence, as evidenced by the epigraphic sources that are preserved to the present, both in criminal and procedural subjects.

\section{KEY WORDS:}

Occupation, epigraphic sources, Ius Gentium, deditium, Ursus Law, actio noxalis. 
Para un mejor entendimiento del objeto de este trabajo, considero fundamental delimitar cronológicamente el concepto que denominamos España prerománica, dejando de lado la denominación de pueblos primitivos o indígenas, pues de estos y especialmente de su interacción jurídica, tenemos poca información. De hecho, la que se posee no está muy lejos de la ocupación romana en la Península Ibérica, realizada en el año 218 A.C. ${ }^{3}$.

Si recogemos los datos arrojados por estudios arqueológicos recientes, la presencia del hombre en España data de hace más de medio millón de años y desde entonces, hasta la ocupación romana, dicho territorio no estuvo integrado por una comunidad homogénea, sino por diferentes pueblos, que llegaron en diferentes épocas, con características étnicas y culturales totalmente diferentes. A la llegada de los pueblos indoeuropeos, como los íberos y los celtas, debe añadirse la de otros, provenientes del Mediterráneo Oriental, como los griegos, fenicios y cartaginenses, quienes modificaron no solo la arquitectura de la zona mediterránea española, de la que aún queda claras muestras, sino que, sin duda, ejercieron influencia en su cultura y normas de convivencia ${ }^{4}$.

3 LALINDE AbADíA, J. Iniciación histórica al Derecho español. 6a . Edición, Barcelona, EUB, 2004, p. 27.

4 Gacto Fernández, E. Manual Básico de Historia del Derecho. Madrid, LAXES, 1997, p. 15. 


\section{Los derechos en la Península Ibérica preromana}

Como adecuadamente apunta Tomás y VALIENTE ${ }^{5}$, existen dos líneas doctrinales en el estudio de la historia del Derecho, unaque en base al pensamiento aristotélico, complementado posteriormente por SANTO Tomás, considera que el ser humano, como animal político, requiere vivir en sociedad y, por tanto, siempre estará regido por normas jurídicas y un poder político natural a éste. Conforme esta línea de pensamiento, siempre existió sociedad, Derecho y política. Otra línea doctrinal se decanta, a su vez, por considerar que el ser humano vivió en un inicio en una suerte de estado de gracia, al cual se refieren los teólogos, o estado de naturaleza -status naturae- para constituir posteriormente un status societatis, como consecuencia del pecado original y en el que la existencia de una autoridad y un Derecho positivo se hacen necesarios. Si algo nos ha enseñado el estudio de los diferentes pueblos primitivos, en diferentes entornos y latitudes, es que siempre existieron estructuras de poder y control social, en donde una clase dirigente tenía la posibilidad de emitir normas y exigir su cumplimiento para asegurarse de la sumisión de una mayoría sometida, ya sea a través de codificaciones de normas, como en el caso de los pueblos sumerios, acadios y semitas o de culturas jurídicas, tal es el caso de la Grecia Micénica. El caso de los pueblos hispanos prerománicos no es diferente, como veremos a continuación.

En primer lugar, nos referimos a los pueblos preromanos, utilizando deliberadamente el plural, pues como ya se analizó anteriormente, fueron varios grupos humanos los que se asentaron

5 Tomás y VAliente, F. Manual de Historia del Derecho Español. Madrid, Tecnos, 2007, p. 71. 
en la Península Ibérica, sin que constituyan una unidad política, cultural y menos aun jurídica. Al parecer, cada uno de ellos tenía un sistema de resolución de conflictos, de base consuetudinaria y religiosa.

Respecto de las manifestaciones jurídicas de estos pueblos, existen fundamentalmente dos fuentes:

a) Las inscripciones epigráficas de diversas clases, entre las que se destacan las tesseras de hospitalidad; y,

b) Noticias literarias de escritores griegos y latinos ${ }^{6}$.

Cuando hablamos de fuentes epigráficas, nos referimos a aquellos objetos que contienen inscripciones, los cuales representan pactos: los pactos o tratados de hospitalidad y las llamadas tesseras de hospitalidad. Los primeros son aquéllos por los cuales una persona o grupo entra a formar parte del derecho de otro y las tesseras son aquellos medios materiales de dichos pactos, hechos de piedra o de algún metal. Varias de éstas se conservan hasta hoy, como el Bronce o tabla de Astorga y el Bronce de Palencia ${ }^{7}$.

Estos pactos permitían reducir los niveles de hostilidad entre diferentes grupos y pueblos y se dividían en pactos de hospicio u hospitalidad propiamente dichos y relaciones de clientela. Los primeros se celebraban en condiciones de igualdad entre las partes, sea entre grupos o entre un individuo y un grupo. Su finalidad,

6 Tomás y Valiente, F. Manual de Historia del Derecho Español... op. cit., p. 75.

7 Morán Martín, R. Materiales para un Curso de Historia del Derecho Español. T. I, Madrid, UNED, 1999, pp. 58-59. 
como lo anota TOMÁs Y VALIENTE ${ }^{8}$, consiste en extender al hospes o huésped el derecho del grupo, a cuya protección se acoge, mientras que las relaciones de clientela se producían cuando el pacto se concertaba entre una parte más débil y otra más fuerte, de manera que el cliente busca la protección jurídica del patrón, a cambio de una relación de sumisión y obediencia, al punto que dentro de la denominada devotio ibérica, el cliente se consagraba a una divinidad para que ésta le aceptase en lugar de la vida del patrono, en tal caso si el patrono moría en combate, el cliente se suicidaba por no haberle cuidado con la debida diligencia. La ruptura del pacto, aun cuando involuntaria, se restablecía con el suicidio.

En cuanto a las fuentes literarias, éstas hacen referencia a los escritos que sobre los pueblos que habitaban la Península Ibérica nos han legado autores griegos y latinos. Sobre ellos debe decirse que la mayoría de los escritos que conocemos son incompletos, dispersos y realizados en diferentes épocas. La gran mayoría fueron de autoría de personas que nunca pisaron el territorio al cual se referían y, menos aun, pudieron interactuar directamente con los pueblos que habitaban en dicha península; es decir, son escritos, basados en testimonios de terceros, como viajeros, comerciantes y soldados, matizados por la perspectiva cultural de quienes los realizaban.

Si en lo jurídico, en general, resulta muy difícil encontrar referencias en lo relacionado con la España preromana, en lo penal lo es aun más todavía. Evidentemente, como en todas las sociedades arcaicas, contaban con un sistema de control social y

8 Tomás y Valiente, F. Manual de Historia del Derecho Español... op. cit., p. 78. 
las manifestaciones de éste, a manera de castigos, deben haberse producido, sin duda. Una referencia que cabe señalar es la expresada por Estrabón, cuando hace referencia a la proliferación de bandas de pillaje, entre los pueblos que habitaban la zona costera, comprendida sobre las tres rías de Coruña, Betanzos y El Ferrol. Al parecer, la vida de aventura y pillaje era bastante frecuente entre los pueblos arcaicos de la Península Ibérica, especialmente los lusitanos, sin embargo, muchos de estos grupos terminaron convirtiéndose en ejércitos de resistencia ante los invasores, como en el caso de Viriato y sus hombres ${ }^{9}$.

De la misma forma, en lo relacionado a la aplicación de penas, al referirse a estos mismos pueblos, se señala que: a los criminales se les despeña, y a los parricidas se les lapida, sacándolos fuera de los límites de su patria o de su ciudad ${ }^{10}$.

9 García Bellido, A. España y los españoles hace dos mil años. 2a. ed. Buenos Aires, Espasa-Calpe, 1945, p. 131.

10 Ibídem, p. 136. 


\section{Romanización jurídica de Hispania}

Cuando hablamos de romanización jurídica, nos referimos al proceso por el cual los diferentes pueblos que habitaban la Península Ibérica, entre el siglo III A.C. y el siglo V D.C., asumieron como propia la estructura jurídica impuesta por Roma. Es un proceso por etapas y toma varios siglos, pues la ocupación es gradual y con diferentes condiciones e intensidades, dependiendo de la zona a la que hagamos referencia. Para muestra vale señalar que cuando los pueblos que habitaban la actual Andalucía, ya llevaban más de dos siglos de dominación romana, las legiones seguían luchando al mando de Augusto para someter los últimos levantamientos de los pueblos del norte ${ }^{11}$.

Para la época de la ocupación romana a la Península Ibérica, se encontraba vigente en Roma la Ley de las XII Tablas (451-449 A.C.), nombre que proviene de su publicación en doce tablas de madera, redactadas por una comisión de diez personas (decemviri legibus scribundis) y su promulgación respondió sobre todo a los reclamos de los plebeyos, porque el Derecho se encontraba fijado por escrito. Muchos de sus preceptos recogían aquellas normas de conducta no escritas, de carácter consuetudinario y nacidas dentro de la comunidad, en el Derecho primitivo de la civitas, denominadas como mores y que a las de mayor jerarquía y respeto se denominaba como mores maiorum, cuya validez religiosa radicaba en la creencia de la comunidad de que éstas representaban aquello que las divinidades consideraban como adecuado y ético. La importancia de las XII Tablas fue tanto jurídica como política, pues representaba la realización

11 Escudero, J. A. Curso de Historia del Derecho. Madrid, Solana e hijos, 1995, p. 110. 
del modelo de convivencia planteado por la polis griega, que implicaba la existencia de normas escritas e igualdad de todos los ciudadanos ante el ordenamiento jurídico ${ }^{12}$. Vale señalar que la interpretación de los mores maiorum se encomendaba al colegio de Pontífices, presidido por el Pontifex Maximus, de los cuales se designaba uno que cada año atendiera los conflictos patrimoniales de los ciudadanos. Esta actividad interpretativa se la denominaba jurisprudencia pontifical ${ }^{13}$.

El Derecho romano republicano se caracteriza por realizar una clara distinción entre ius y lex, así el primero tiene relación con iudex, iudicium, iudicare, iudicatio, términos que harían pensar en un origen procesal del Derecho y que éste se hubiera construido en base a casos específicos (FALLRECHT) ${ }^{14}$, así como a aquello que se consideraba como justo, esto es a la iustitia, que se remonta a la suprema justicia de los dioses y es por tal razón que las primeras manifestaciones del ius en Roma suponen una justicia divina, cuyos intérpretes son los sacerdotes, como hemos visto anteriormente ${ }^{15}$.

La Lex, por su parte, se refiere al concepto de norma objetivada, es decir, la fijación de un precepto que vincula porque se ha establecido de manera adecuada y cuyos requisitos formales son inmanentes a ella, que ha de ser objeto de dicere, dare o rogare.

12 Paricio, J. y Fernández Barreiro, A. Historia del Derecho Romano y su recepción europea. Madrid, Ramón Areces S.A., 1997, p. 59.

13 Betancourt, F. Derecho Romano Clásico. Sevilla, Universidad de Sevilla, 2001, p. 46.

14 KASER, M. Das altrömische ius: Studien zur Rechtsvorstellungund Rechtsgeschichteder Römer. Göttingen, Vandenhoeck \& Ruprecht, 1949, p. 63 y ss.

15 FuentesecA, P. Historia del Derecho Romano. Madrid, Europa Artes Gráficas, 1987, p. 186 y ss. 
A través de la Lex, se realiza el ius y constituyen las dos caras del sistema jurídico, sin perderse de vista el origen religioso de aquello que se consideraba como jurídico y legal, en la que los sacerdotes son los encargados de adivinar la voluntad divina y por esa vía interpretar jurídicamente las normas ${ }^{16}$. Vemos que en esto existe coincidencia con el proceso de interpretación y aplicación de la Ley en el pueblo hebreo, en el cual son justamente los sacerdotes, miembros de la tribu de Leví, a quienes se les delega esa función ${ }^{17}$.

El Ius, entendido como sistema jurídico, se manifestaba fundamentalmente entre órdenes, el Ius civile, el Ius honorarium y el Ius gentium. El primero es, sobre todo, el Derecho propio de los ciudadanos romanos y solo aplicable a ellos. Los extranjeros no tenían acceso a él, salvo que se les hubiera concedido el commercium, que les habilitaba para ciertas relaciones jurídicas y el conubium, que les posibilitaba contraer matrimonio ${ }^{18}$. Este sistema jurídico regulaba las relaciones jurídicas entre los pater familiarum y contemplaba tanto los aspectos sustantivos, como los procesales. Estaba compuesto en la república fundamentalmente por los mores maiorum, las XII Tablas y nuevas fuentes del Derecho, como los senado consultos, los edictos de los magistrados y mención especial merece la ley pública, votada por el pueblo en los comicios $^{19}$.

16 Fuenteseca, P. Historia del Derecho Romano... op. cit., p. 187.

17 García Falconí, R. y Larenas, M. Los albores del Derechos Penal en Derecho penal y Criminología. Bogotá, Universidad Externado de Colombia, 2016.

Paricio, J. y Fernández Barreiro, A. Historia del Derecho Romano y su recepción europea... op. cit., p. 88.

Rascón García, C. Manual de Derecho Romano. $2^{\mathrm{a}}$. ed., Madrid, 
En cuanto al Ius honorarium, éste se crea con la función de renovación y adaptación del Derecho romano a las nuevas condiciones económico-sociales. Se le denomina así al Derecho creado por los magistrados encargados de la administración de la justicia, fundamentalmente el pretor y secundariamente, en ámbitos específicos a los ediles curules, se consideraba un honor al ejercicio de una magistratura y de ahí el nombre de honorario $^{20}$. Los edictos de los pretores fueron muy importantes, especialmente en materia civil, pues tuvo una influencia notable en el desarrollo del ordenamiento jurídico romano y de manera especial en el procesal, puesto que constituían una suerte de promesas de protección de derechos que antes del edicto no estaban reconocidos ${ }^{21}$.

Finalmente, el Ius Gentium se desarrolla en Roma como consecuencia del intercambio con otros pueblos, sobre todo en el ámbito comercial. Su denominación no alude a un Derecho extranjero, sino a un Derecho romano accesible para los extranjeros ${ }^{22}$. Es un forma de Derecho romano internacionalmente aplicable a quienes, no siendo ciudadanos romanos, mantienen relaciones jurídicas con Roma, ya sea por actividades de comercio o simplemente por habitar en ella sin ser ciudadanos. Las relaciones jurídicas entre los romanos y los peregrinos y entre ellos se regulaban a través de este sistema. Un aspecto interesante es la acepción que le da Gayo al Ius Gentium, quien

Tecnos, 1996, p. 83.

20 De Churruca, J. Introducción histórica al Derecho Romano. Bilbao, Universidad de Deusto, 1994, p. 97.

21 Rascón García, C. Manual de Derecho Romano... op. cit., p. 87.

22 Paricio, J. y Fernández BARReiro, A. Historia del Derecho Romano y su recepción europea... op. cit., p. 93. 
señala que:

Todos los pueblos se rigen por leyes y costumbres y usan en parte su propio derecho y en parte el derecho común de todos los hombres; pues el derecho que cada pueblo establece para sí, ese es suyo propio, y se llama derecho civil [...]; en cambio, el que la razón natural establece entre todos los pueblos y se llama derecho de gentes, como dijéramos que es el derecho que usan todas las naciones ${ }^{23}$.

Esta división es importante para el objeto de estudio del presente trabajo, pues la relación jurídica de Roma y los pueblos que habitaban la Península Ibérica fue desarrollándose progresivamente a lo largo de los siglos y modificando su estructura y contenidos.

En el caso de los pueblos hispanos, así como de otros a los que Roma sometió, se diferenciaba entre aquéllos que aceptaron pacíficamente su hegemonía, con quienes firmaron tratados (foedera) y aquéllos otros que ofrecieron resistencia militar y que debieron ser sometidos por la fuerza, a quienes se les exigía la rendición incondicional (deditio). En el caso de la foedus o pacto, debe señalarse que Roma, en principio, respeta la organización propia de los pueblos que conquista, siempre que no se opongan a ella. Es un pacto que se hacía con un general romano y en muchos casos fue entendido como un tipo de tratado de hospitalidad, lo cual no corresponde realmente con el sentido de dichos acuerdos, pues en el caso de los pactos equitativos (foedus aequum), se

23 PETIT, E. Tratado elemental de Derecho Romano. México, Editora Nacional, 1969, § 6.2.b. 
firmaban en un marco de amistad y cierta igualdad, pero en los pactos inícuos (foedus iniquum) se acordaba una sumisión sin ambages a la soberanía romana. Cualquier acto que los romanos pudieran considerar como una forma de rompimiento del acuerdo les liberaba de sus obligaciones de respeto y podían constituir el motivo para una intervención armada, como en el caso de la ciudad de Segeda, en la que se pretendió construir una muralla, que los romanos entendieron como una forma de romper los pactos suscritos con Semponio Graco ${ }^{24}$.

La deditio constituye el desenlace de la resistencia armada, de quienes han decidido no capitular, que tenía fundamentalmente el carácter de rendición incondicional, de manera tal que las ciudades vencidas bajo este régimen quedan como ciudades dediticias, que unas veces subsisten pagando un tributo a Roma y otras son simplemente arrasadas y sus habitantes esclavizados, como en el caso de Numancia en el año 133 A. C. ${ }^{25}$.

Es en el 19 A. C. que se produce la conquista total de la Península Ibérica, con el sometimiento de cántabros y astures, por parte de Augusto, dos siglos después del primer desembarco romano. Durante todo este tiempo, los habitantes de la península fueron considerados peregrinos y eso no cambió hasta el año 73 ó 74 de nuestra era, cuando el emperador Vespasiano concede la latinidad a toda España ${ }^{26}$ y de cuyo contenido no queda más referencia que la de un texto de Plinio en su Historia Natural ${ }^{27}$.

24 Escudero, J. A. Curso de Historia del Derecho ... op. cit., p. 111.

25 Íbidem, p. 111.

26 Lalinde Abadía, J. Iniciación histórica al Derecho español. 6a. ed., ... op. cit., p. 61.

27 Universiae Hispaniae. Vespasianus Imperator Augustus, iactatum 
Posteriormente, en el 212 el emperador Antonio Caracalla promulga una Constitución, en la cual otorga la ciudadanía romana a todos los súbditos del imperio, según el texto que conocemos de ésta y con el cual concluye el proceso de romanización de los pueblos que habitaban la Península Ibérica ${ }^{28}$.

Si bien el otorgamiento de la ciudadanía a todos los habitantes de la Hispania romana los ubicaría bajo la égida jurídica del Imperio, son pocas las evidencias de la aplicación del Derecho romano. Uno de los aspectos fundamentales de la concesión de la ciudadanía a todos los súbditos del Imperio Romano, por parte de Caracalla, es el de eliminar la diferenciación existente, hasta ese entonces, entre ciudadanos latinos y peregrinos, cobrando fuerza la mera distribución social, llamándose honestiores a los de clase social alta y humiliores a los de clase inferior ${ }^{29}$.

Las leyes que se emitieron y de las que existe constancia son fundamentalmente municipales, como la Ley de Urso, también conocida como Lex coloniae Genetivae Juliae, que dataría del

procellis rei publicae latium tribut.

Es menester ante todo referirá la divinidad las causas y motivos (de nuestros hechos); también yo tendría que dar gracias a los dioses inmortales porque con la presente victoria me honraron y guardaron salvo. Asi, pues, creo de este modo poder satisfacer con magnificencia y piedad su grandeza al asociar el culto de los dioses a cuantos miles de hombres se agreguen a los nuestros. Otorgo, (pues), a todos cuantos se hallan en el orbe de la ciudadanía romana, sin que quede nadie sin una ciudadanía excepto los dediticios. En efecto, conviene que todos, no solo contribuyan en todo lo demás, sino que participen también de la victoria. Y esta constitución manifiesta la grandeza del pueblo romano [...]. D'ORS, A. Epigrafía jurídica de la España romana (Trad.). Madrid, Instituto Nacional de Estudios Jurídicos, 1953, p. 203.

EsCudero, J. A. Curso de Historia del Derecho... op. cit., p. 118. 
44 A. C.; se conservan de ésta unos cincuenta capítulos en cuatro bronces $^{30}$; contiene varias disposiciones de naturaleza penal, de las que ya nos ocuparemos más adelante. De la misma forma, la Lex Salpensana y la Lex Malacitana, de la cual se han descubierto fragmentos muy pequeños, que no nos permiten tener una idea cabal de su contenido original, al igual que varios fragmentos de cuerpos normativos, entre los cuales cabe destacar los Fragmentos hispalenses, pues en la parte que ha sido conservada, se refiere a la obligación de devolver los fondos que se tuvieran de la caja municipal en los treinta días siguientes a su recepción y a la necesidad de rendir cuentas de los negocios realizados con dinero del municipio ante los decuriones, quienes podían sancionar a los que hubieran incumplido esta norma o defraudado alguna suma. Estos fragmentos, se presume, datan del siglo $\mathrm{I}^{31}$.

Ésta y otras leyes regulaban diferentes aspectos de la vida en comunidad del pueblo a las que estaban destinadas y tenían varias disposiciones con contenido penal, como analizaremos a continuación.

30 Gacto Fernández, E. Manual Básico de Historia del Derecho... op. cit., p. 42.

31 Fernández Nieto, F. J. "El Derecho en la España romana", en MenÉndez PIDAL, R. Historial de España. T. II, Madrid, XX, EspasaCalpe, 1982, p. 185. 


\section{El Derecho penal romano imperante durante la ocupación de la Península Ibérica}

Conforme se ha señalado anteriormente, la ocupación de la Península Ibérica por parte de Roma inicia en el 218 A. C., con el desembarco del ejército romano en Ampurias, es decir, en la época republicana. La dominación romana sobre los pueblos hispanos durará hasta el siglo $\mathrm{V}$ de nuestra era, en la cual se produce la denominada invasión de los bárbaros y, por tanto, la caída del Imperio Romano de Occidente. En el caso de la Península Ibérica, la transición jurídica se produce con la llegada de los visigodos, como consecuencia de la firma de un acuerdo con Roma en el 418, por el cual recibieron tierras en Aquitania y posteriormente en el año 507, se trasladaron hacia el sur, luego de ser derrotados por los francos, hasta situar Leovigildo, su capital, en Toledo (entre los años 568 y 586). En tal virtud, la dominación romana sobre los pueblos asentados en la Península Ibérica duró casi seis siglos, durante los cuales no solo se produjeron cambios políticos, sino también jurídicos, que, para los propósitos de este trabajo, son los que deben considerarse como relevantes.

A la llegada de los romanos a la actual España, Roma era una república en crisis económica, en la que la desigualdad en el reparto de los recursos generó una serie de tensiones entre la clase dominante y el pueblo llano, que entra en un proceso de progresiva pauperización, agravada sobre todo en el siglo II A. C. ${ }^{32}$. En esa época, el Derecho penal imperante, si es que se puede llamar así al sistema de aplicación de castigos, al igual que en las demás sociedades arcaicas, va íntimamente ligado a

32 Paricio, J. y Fernández Barreiro, A. Historia del Derecho Romano y su recepción europea... op. cit., p. 99. 
lo religioso. En Roma, la distinción entre ius y fas, entendida la primera como norma que determinaba lo lícito, conforme al criterio de los hombres, y el segundo, como la medida de lo que era o no propicio a los dioses, de manera que lo que actualmente denominamos como Derecho penal, siempre estuvo impregnado de un componente mágico-religioso, por el que era la pax deorum el interés máximo que una sociedad debía proteger; la sanción, además de constituirse en un castigo a una conducta ilícita, tenía la propiedad de aplacar a los dioses y su función expiatoria era fundamental ${ }^{33}$.

Muchas de las infracciones cometidas en esaépoca se consideraban expiadas con el piaculum, ofrenda sacrificial o entrega de una cantidad patrimonial. Tales los casos como el de la viuda que contrajere nupcias antes de haber transcurrido un año de luto, la concubina que hubiera violado la prohibición de tocar el altar de Juno o el marido que, sin justa causa, hubiera repudiado a su mujer. En este último caso, debía entregar al culto de Ceres la mitad de su fortuna y la otra mitad, a la mujer indebidamente repudiada ${ }^{34}$.

El piaculum, sin embargo, no era suficiente para expiar la ira de los dioses, en todo tipo de delitos, pues la responsabilidad penal de mayor gravedad exigía que el transgresor responda con su propia persona y, eventualmente, con sus bienes frente a la ofensa. A esto se denomina como la scelus inexpiable. De los testimonios existentes hasta la fecha, aparecen dos formas de manifestarse

33 Rascón García, C. Manual de Derecho Romano. Madrid, Tecnos, 1996, p. 136.

34 Santalucía, B. Derecho Penal Romano. Madrid, Ramón Areces S.A., 1990, p. 28. 
el castigo sacralizado o supplicium, como se le denomina en clara referencia a su finalidad expiatoria asignada a la pena. Por una parte, el abandono de la persona que hizo la transgresión y la entrega de sus bienes al dios ultrajado (consecratio capitis et bonorum) y por otra, la pena de muerte considerada también como sacrificio expiatorio (deo necari $)^{35}$.

Uno de los primeros temas que debe tomarse en cuenta es que en el Derecho penal romano, el concepto de delito requiere la existencia de una voluntad contraria a la ley en la persona capaz de obrar, la cual no rigió en los primeros tiempos, aunque posteriormente se consideró como fundamental a la voluntad antijurídica del agente; asimismo, tampoco existe delito alguno si esta voluntad no se concreta en un hecho punible ${ }^{36}$.

En el Derecho penal, como en las demás áreas jurídicas, la relación de éste con lo mágico-religioso es una constante. La forma en que se imponían las penas y las conductas, consideradas como delitos, nos remiten necesariamente a una concepción expiatorio - religiosa de la pena; baste recordar que las vestales, que violaban su voto de castidad, eran enterradas vivas, así como también se ejecutaba a aquéllos que hacían encantamientos para provocar la muerte de otro ${ }^{37}$. De igual forma, en delitos como el parricidio o el perduellio, se imponía la pena de muerte, pero dentro de ritos de claro sesgo expitario - religioso; así, al parricida y al reo de perduellio se les colgaba del árbol infelix, que era aquel que no

35 Santalucia, B. Diritto e proceso penale nell' antica Roma. Milán, Giuffré, 1989, p. 4.

36 Mommsen, T. El Derecho Penal Romano. Dorado Pedro (Trad.). Madrid, La España Moderna, pp. 94 y 103.

37 Rascón García, C. Manual de Derecho Romano. ...op. cit., p. 138. 
tenía frutos o cuyos frutos no eran comestibles, pero que además se consideraban de mal augurio, como los de frutos negros, las zarzas y todos aquéllos que entonces se consideraban bajo la protección de dioses infernales ${ }^{38}$.

La sanción religiosa más frecuente era la sacratio capitis, con la cual se consagraba el delincuente a la divinidad, en consecuencia, el declarado homo sacer, objeto de la sacratio, pasaba a ser propiedad de los dioses, es decir, cualquier ciudadano podía privarle de su vida y de esta manera, expiar el delito cometido ${ }^{39}$.

El Derecho penal romano tiene como fundamento la coercitio del magistrado, que consiste en una facultad de decidir respecto de la imposición de castigos y es parte de su poder global, denominado como imperium, con el cual se encontraban investidos, tanto el rey, como los magistrados republicanos ${ }^{40}$. Este poder se limitó, desde finales del siglo IV A. C., por la posibilidad de recurrir ante la asamblea del pueblo, mediante la provocatio ad populum. Hasta el siglo IV A. C., además de la coercitio del magistrado, se celebraban determinados procesos ante el pueblo reunido en asamblea; a partir de este siglo, aparecen las primeras questiones extraordinariae, como tribunales constituidos con carácter extraordinario, ante los que se celebran procesos públicos para redimir conductas consideradas como contrarias a los intereses de la colectividad, constituyendo el precedente de las questiones

38 CAntarella, E. Los suplicios capitales en Grecia y Roma. Madrid, Akal, 1996, p. 165.

39 KASER, M. Das altrömische ius: Studien zur Rechtsvorstellungund Rechtsgeschichteder Römer. ...op. cit., p. 72.

40 FuenteseCA, P. Historia del Derecho Romano. ... op. cit., p. 214. 
perpetuae o tribunales permanentes, creadas a partir del siglo II A. C. para juzgar los crimina ${ }^{4 l}$.

Un aspecto de enorme interés, que cabe resaltar del análisis histórico del Derecho penal romano, es la constante lucha del pueblo por limitar y controlar el poder punitivo ejercido por los magistrados y los tribunales especiales creados, sobre todo dentro del esquema de las questiones extraordinariae; así, a partir de la Lex Sempronia de capite civis, votada en el 123 A. C., propuesta por Cayo Graco, todas las questiones extraordinariae debieron ser creadas con la participación del pueblo, se aplicó la provocatio ad populum en el sentido de que no se podía imponer una pena de muerte sin contar con la asamblea ${ }^{42}$.

Este principio de que una pena de muerte no puede ser impuesta a un ciudadano, sino a través de un juicio de la asamblea, tuvo ya un antecedente en las XII Tablas, la cual estableció un regla, según la cual, cuando estuviera en juego la vida de un ciudadano, dicha decisión debía reservarse a los comicios centuriados, pues, de acuerdo a lo señalado posteriormente por Cicerón ${ }^{43}$, esta norma tendría su antecedente en una lex sacrata o deliberación jurada de la comunidad plebeya, motivada sobre todo por la utilización de los procesos capitales utilizados como arma política del patriciado, respecto de lo cual la plebe luchó para que esta atribución fuera transferida a la asamblea por curias (de capite civis nisi per máximum comitiatum ne ferunto); por su parte, los patricios consiguieron insertar en el código decenviral el precepto que prohibía ejecutar a una persona que no hubiese sido

\footnotetext{
41 Rascón García, C. Manual de Derecho Romano. ... op. cit., p. 138.

42 Rascón García, C. Manual de Derecho Romano. ... op. cit., p. 138.

43 CíERÓn. pro Sestio, pp. 30 y 65.
} 
condenada regularmente (indemnatum hominem interfici), con lo cual se previno a futuro los procesos capitales revolucionarios dirigidos por los tribunos ante los concilia plebis ${ }^{44}$.

Otro aspecto que debe analizarse, teniendo en cuenta los dos siglos que duró la pacificación de los pueblos ibéricos, por parte de los ejércitos romanos, hasta la victoria de Augusto en el 31 A. C., es el paralelismo existente entre el Derecho penal romano común y el Derecho de la guerra. En principio debe reconocerse que en buena parte los hechos punibles, según el Derecho de la guerra, eran los mismos delitos contra el estado, que establecía la legislación común a todos, sin embargo, conductas como la desobediencia a los mandatos de los magistrados, que en la legislación común no se tipificaba como delito, se consideraba una falta de enorme gravedad en el ejército. Los delitos sexuales, que no se consideraban como tales en la época republicana, así como el hurto, que merecía apenas una sanción pecuniaria, en el Derecho de guerra se consideraban delitos capitales, pues se estimaba que la lujuria relajaba la disciplina militar, así como el hurto cometido en el campo de batalla ${ }^{45}$.

Las penas también diferían, pues aunque la pena de muerte se encuentre en primer lugar, tanto en las normas comunes, como en las militares, las penas corporales y de manera especial la flagelación fueron utilizadas de forma recurrente en el Derecho de guerra romano, así como la prisión como medio de disciplina militar.

\footnotetext{
44 Santalucia, B. Derecho Penal Romano. ... op. cit., p. 47.

45 Mommsen, T. El Derecho Penal Romano. Pedro Dorado, (Trad.). ... op. cit., p. 33.
} 
Son pocos los textos en los que se recoge aspectos puntuales del Derecho penal en la Hispania romana, sin embargo, como ya se señaló anteriormente, hay algunos aspectos puntuales que podemos apreciar, tanto en constituciones imperiales, como en leyes municipales, en las que se hace la diferenciación entre delicta y crimina, de acuerdo a aquello que se define como privado y público, división que, tanto en lo sustancial, como en lo adjetivo siempre fue difusa y sujeta a interpretación.

En cuanto a los posibles autores de los delitos, de acuerdo a los textos municipales, puden ser, tanto hombres libres, como esclavos, siendo estos últimos responsables por sí mismos, independientemente de la responsabilidad de su dueño. Con seguridad, la fuga de esclavos debió ser frecuente, pues existe una constitución imperial del año 332 sobre los esclavos fugitivos para las Hispanias ${ }^{46}$.

La Ley de Urso establece, en su capítulo 122 de manera fragmentaria, el delito de hurto cometido por un esclavo, lo cual daba lugar, seguramente, a una acción directa contra el esclavo o contra éste y su dueño, en caso de haber existido complicidad para el cometimiento del delito, en lugar de la actio noxalis ${ }^{47}$. Normalmente el dominus respondía por los delitos cometidos por el servus, ya que la acción noxal no podía dirigirse propiamente contra éste ${ }^{48}$. La responsabilidad

46 Morán Martín, R. Materiales para un Curso de Historia del Derecho español. T. I., Madrid, Universidad Nacional de Educación a Distancia, 2010, p. 191.

47 Fernández Nieto, J. Historia De España Antigua. T. I: Protohistoria. Madrid, Cátedra, 2012, p. 143.

Navarro-Hortelano, C. "Similitudines en supuestos de Noxae deditio 
noxal facultaba al propietario del esclavo a pagar la litis aestimatio o a entregarlo a la víctima del delito ${ }^{49}$, bajo el principio general noxa caput sequitur ${ }^{50}$. De acuerdo a esta facultad, se pueden establecer tres alternativas: en primer lugar, la noxae deditito caput sequitur y el pago de la pena in solutione; la obligación noxal como posibilidad con dos objetos simultáneos y; finalmente, el pago de la pena como obligación principal y la noxae deditio como solutionis ${ }^{51}$.

La misma Lex Ursus o Ley de Urso, en su capítulo 75, se refiere al daño en los edificios, estableciendo una sanción proporcional a éste. Los Bronces de Vipasca, asimismo, tipifican el hurto de mineral (II, 9 y 10) y los delitos de peculatus o furtum de bienes estatales $^{52}$. En cuanto al abigeato, el rescripto de Adriano derivaba en que el consilium provincial solicite información sobre el tipo de castigo que debía ser aplicado a los cuatreros o bandas de ladrones especializadas en el robo de ganado ${ }^{53}$, el cual incluía practicas similares como la sustracción del establo o lugar de pasto; las circunstancias de comisión del delito podían

servi fructuarii", en Boletín de la Facultad de Derecho. N. ${ }^{\text {1 } 14}$, Madrid, Universidad Nacional de Educación a Distancia, 1999, p. 229.

49 GiRARD. "Les actiones noxales", en Nouvelle Revue Historique du Droit Francais et Etranger. París, Onziéme Année, 1887, p. 409 y ss.

50 D`ors, J. Derecho Privado Romano. Pamplona, 1997, \&373 nt. 1.

51 GIRARD. "Les actiones noxales", en Nouvelle Revue Historique du Droit Francais et Etranger. ...op. cit., p. 47; LENEL, O. "Die Formeln der Actiones noxales", en ZSS, 1927, p. 29.

52 Morán Martín, R. Materiales para un Curso de Historia del Derecho español. T. I, ... op. cit., p. 192.

53 PAVón, P. "De abigeis puniendis: el rescripto de Adriano sobre el robo de ganado en la Bética", en Gerión 28. N. 1, Junta de Andalucía, 2010, p. 276. 
acarrear la pena de trabajo forzado hasta de forma permanente ${ }^{54}$. El rescripto de Antonio Pío al preconsul de la Bética, en relación a los delitos de honestidad, sancionaba a los dueños de esclavos que los obliguen a realizar actos indecorosos que deriven en su propia venta $^{55}$. La regulación del Estado, a través de los gobernadores provinciales, les proveía credenciales y en caso de ser necesario, de un apparitor; incluso, la imposición de castigos en caso de oposición $^{56}$. El segundo rescripto de este emperador incluyó limitaciones a la huida, a través de luchas con fieras en el circo, que podían o no desembocar en la devolución a sus dueños; el desarrollo jurídico de estos cuerpos legales se centró en una casuística diferente, cuya proyección especifica fue la esclavitud ${ }^{57}$.

En Roma, los delitos religiosos y aquéllos que actualmente denominamos como delitos contra la salud pública, tenían relación con las prohibiciones de introducir cadáveres en la ciudad, dar sepultura e incinerar los cadáveres. La Ley de Urso contemplaba la descripción de estas conductas, en su capítulo 73 , sin concordancia con las prácticas sociales y culturales de la época, tales como inhumar a los familiares en casa, provenientes de las XII Tablas, que fueron prohibiéndose y aplicadas por excepción $^{58}$.

54 Garcia del Corral, I. Cuerpo del Derecho Civil Romano. Barcelona, 1889.

55 Morán Martín, R. Materiales para un Curso de Historia del Derecho español. T. I, ... op. cit., p. 192.

56 GonzÁles Román, C. "El rescripcto de Antonino Pío sobre los esclavos de Iulius Sabinus de la Bética", en Gerón 21. N. ํ. Granada, Departamento de Historia Antigua de la Universidad de Granada, 2003, p. 355.

57 Gonzáles Román, C. “El rescripcto de Antonino Pío sobre los esclavos de Iulius Sabinus de la Bética", en Gerón 21. N. 1, ...op. cit. p. 355.

LóPEZ MeLero, R. Enterrar en Urso (Lex Ursonensis LXXIII-LXXIV). 
En cuanto a los temas urbanísticos o ambientales, se penalizó el almacenamiento de tejas y construcción de fábricas, la razón era ajena a criterios de seguridad, sino que se enfocaba en la prevención de futuras rebeliones en las que grandes cantidades de tejas sean utilizadas con fines defensivos contra la autoridad central; los efectos penológicos de estas acciones iban desde la confiscación, hasta la venta de los inmuebles, cuya cantidad formaría parte de la hacienda pública ${ }^{59}$.

Los delitos derivados de la mala gestión de fondos públicos, tanto en colonias, como en municipios se penalizaban con multas y la inhabilitación de los puestos en las magistraturas ${ }^{60}$. La tipificación de estos delitos es el resultado de una tradición, que nace de una legislación sobre el crimen repetundarum, seguida por la lex ursonensis y la posterior lex flavia municipalis, lex irnitana y lex Malaca, describiendo las conductas de concusión, tráfico de influencias, peculado, aceptación de regalos, gratificación a los allegados por concesión de un bien público, participación en subastas de arriendos de tierras públicas y ventas del patrimonio de los municipios ${ }^{61}$.

S.H. Monográfico, N. ${ }^{\circ}$ 5, pp. 115-118.

59 Morán Martín, R. Materiales para un Curso de Historia del Derecho español. T. I, ... op. cit., p. 193.

60 MorÁn Martín, R. Materiales para un Curso de Historia del Derecho español. T. I, ...op. cit., p. 192.

61 García GARrido, M. “La concusión y el tráfico de influencias en la lex ursonensis y en las leyes municipales", en Stvd. Historia Antigua 15. Salamanca, Ediciones Universidad de Salamanca, 1997, p. 97. 


\section{El Derecho procesal romano en Hispania}

La diferenciación que existe entre los juicios privados, en donde el magistrado tiene una acción de dirigir la actuación de los sujetos, y los juicios públicos, asistidos en un proceso de los crimina, iniciado por el gobernador provincial y los emperadores, implica una relación similar a la que existe entre el Derecho penal y el Derecho procesal.

La ley de Urso recoge una serie de figuras procesales como la supervivencia de las antiguas legis actiones, en especial la manus iniectio y el uindex; la aplicación de la actio petitio persecutio constituyó un problema al considerarse arcaica, ya que interviene para librar a quien adeuda y que posteriormente sufriría alteraciones ${ }^{62}$. El tratamiento que se debía dar a los esclavos incluía disposiciones manumissio auindicta, en el caso de menores o mujeres donde se requería la intervención de un duouir 63 .

El aspecto procedimental de los municipios de la Bética lo podemos encontrar en la Lex Irnitana, que situaba a los duo iuri iure dicundo, bajo la administración de estas localidades, con el rol de citar a los testigos, nombrar a los jueces, recuperadores o árbitros de las causas, publicar edictos, fórmulas judiciales y demás documentos provinciales del gobernador, que pudiesen afectar a su jurisdicción; situación que, en terminos generales,

62 Morán Martín, R. Materiales para un Curso de Historia del Derecho español. T. I, ...op. cit., p. 192.

63 BARJA DE QUIROGA, L. "Estructura compositiva de la lex ursonensis", en Stvd. Historia Antigua 15. Salamanca, Ediciones Universidad de Salamanca, 1997, p. 51. 
se encuentra a cargo de la figura del dunuiri en un plazo de tres días ${ }^{64}$.

En la época repúblicana, la responsabilidad de revisión de multas correspondía a los comicios, es decir, los cargos en la escala política en orden ascendente duviros, ediles y cuestores en razón del orden de importancia de las magistraturas ${ }^{65}$. En Hispania, el encargado de las multas era el senado municipal a quien se le sumaba varias competencias correspondientes al gobernador, específicamente con respecto a delitos con penas graves ${ }^{66}$. Cabe recalcar que los delitos de concusión y tráfico de influencias, que constan en la lex de Urso, lex de Irni y su relación con las leges calpurnia de pecuniis repetundis, lex aulia repetundarum, lex iulia iudiciorum publicorum, lex iulia iudictorum privatorum, nos acercan a las llamadas acciones populares ${ }^{67}$.

Finalmente, el desarrollo del Derecho procesal llevó a que las acciones populares se caractericen por ser extraordinarias y se perfeccionen en un ejercicio ordinario y privado, cuyo fin era precautelar la organización pública ${ }^{68}$. Por otro lado, el

64 Morán Martín, R. Materiales para un Curso de Historia del Derecho español. T. I, ...op. cit., p. 194.

65 MentXAKA, R. "Los requisitos para acceder a las magistraturas locales con base en los escritos de los juristas clásicos", en Veleia 28 9-67. Grupo de Investigación del sistema universitario vasco, 2011, p. 31.

66 Morán Martín, R. Materiales para un Curso de Historia del Derecho español. T. I, ...op. cit., p. 194.

67 García Garrido, M. “La concusión y el tráfico de influencias en la lex ursonensis y en las leyes municipales", en Stod. Historia Antigua 15. ...op. cit., p. 97.

68 Morán Martín, R. Materiales para un Curso de Historia del Derecho 
procedimiento privado por fórmulas tuvo su origen en provincias con características propias hasta configurar un tertium genus del proceso popular o recuperatorio, constituyéndose como un punto medio, entre lo público y privado, con fases del proceso civil (ordo y cognitio) como son: acciones de ley, formulario y extraordinario, incluso, el impacto de las quaestiones perpertuae y el proceso administrativo multae dictio $^{69}$.

español. T. I, ...op. cit., p. 196.

69 García Garrido, M. El Derecho Privado Romano. Casos, acciones, instituciones. Madrid, Dykinson, 1997, p. 112. 


\section{BIBLIOGRAFÍA}

BARJA DE QUIROGA, López. "Estructura compositiva de la lex ursonensis", en Stvd. Historia Antigua 15. Salamanca, Ediciones Universidad de Salamanca, 1997.

BetAnCOURT, Fernado. Derecho Romano Clásico. Sevilla, Universidad de Sevilla, 2001.

CANTARElla, Eva. Los suplicios capitales en Grecia y Roma. Madrid, Akal, 1996.

CICERÓn. pro Sestio.

D’ORS, Álvaro. Epigrafía jurídica de la España romana. Madrid, Instituto Nacional de Estudios Jurídicos, 1953. . Derecho Privado Romano. Pamplona, 1997.

DE CHURRUCA, Juan. Introducción histórica al Derecho Romano. Bilbao, Universidad de Deusto, 1994.

ESCUDERO, José Antonio. Curso de Historia del Derecho. Madrid, Solana e hijos, 1995.

FERNÁNDEZ NIETO, Francisco Javier. "El Derecho en la España romana”, en MENÉNDEZ PIDAL, Ramón. Historial de España. Tomo II, Madrid, Espasa-Calpe, 1982.

. Historia De España Antigua. Tomo I: Protohistoria. Madrid, Cátedra, 2012. 
FueNTESECA, Pablo. Historia del Derecho Romano. Madrid, Europa Artes Gráficas, 1987.

GACTO FERNÁNDEZ, Enrique. Manual Básico de Historia del Derecho. Madrid, LAXES, 1997.

GARCÍA BELlido, Antonio. España y los españoles hace dos

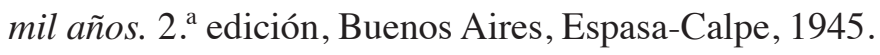

GARCÍA DEL CORRAL, Ildefonso. Cuerpo del Derecho Civil Romano. Barcelona, 1889.

GARCíA FALCONÍ, Ramiro, y LARENAS, Melissa. "Los albores del Derechos Penal", en Derecho penal y Criminología. Bogotá, Universidad Externado de Colombia, 2016.

GARCÍA GARRIDO, Manuel. El Derecho Privado Romano. Casos, acciones, instituciones. Madrid, Dykinson, 1997.

- "La concusión y el tráfico de influencias en la lex ursonensis y en las leyes municipales", en Stvd. Historia Antigua 15. Salamanca, Ediciones Universidad de Salamanca, 1997.

GIRARD. "Les actiones noxales", en Nouvelle Revue Historique du Droit Francais et Etranger. Paris, Onziéme Année, 1887.

GONZÁLES ROMÁN, Cristóbal. "El rescripcto de Antonino Pío sobre los esclavos de Iulius Sabinus de la Bética", en Gerón 21. N. ${ }^{\circ}$ 1, Granada, Departamento de Historia Antigua de la Universidad de Granada, 2003. 
KASER, Max. Das altrömische ius: Studien zur Rechtsvorstellungund Rechtsgeschichteder Römer. Göttingen, Vandenhoeck \& Ruprecht, 1949.

LALINDE ABADÍA, Jesús. Iniciación histórica al Derecho

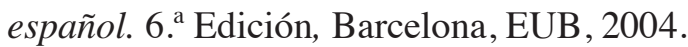

LÓPEZ MELERO, R. Enterrar en Urso (Lex Ursonensis LXXIIILXXIV). S. H. Monográfico, N. ${ }^{\circ} 5$.

MENTXAKA, Rosa. "Los requisitos para acceder a las magistraturas locales con base en los escritos de los juristas clásicos", en Veleia 28 9-67. Grupo de Investigación del sistema universitario vasco, 2011.

MOMMSEN, Teodoro. El Derecho Penal Romano. PEDRO DORADO (Trad.). Madrid, La España Moderna, 1898.

MORÁN MARTÍN, Remedios. Materiales para un Curso de Historia del Derecho español. Tomo I, Madrid, UNED, 1999.

- Materiales para un Curso de Historia del Derecho español. Tomo I, Madrid, Universidad Nacional de Educación a Distancia, 2010.

NAVARRO-HORTELANO, Carolina. "Similitudines en supuestos de Noxae deditio servi fructuarii”, en Boletín de la Facultad de Derecho. N. ${ }^{\text {14, Madrid, Universidad }}$ Nacional de Educación a Distancia, 1999. 
Rev. CAP Jurídica Central N. 4 - agosto 2019, ISSN 2550-6595

PARICIO, Javier y FERNÁNDEZ BARREIRO, A. Historia del Derecho Romano y su recepción europea. Madrid, Ramón Areces S.A., 1997.

PAVÓN, Pilar. "De abigeis puniendis: el rescripto de Adriano sobre el robo de ganado en la Bética", en Gerión 28. ․․ 1, Junta de Andalucía, 2010.

PETIT, Eugene. Tratado elemental de Derecho Romano. México, Editora Nacional, 1969.

RASCÓN GARCÍA, César. Manual de Derecho Romano. Madrid, Tecnos, 1996.

SAntalucía, Bernardo. Derecho Penal Romano. Madrid, Ramón Areces S.A., 1990.

. Diritto e proceso penale nell' antica Roma. Milán, Giuffré, 1989.

TOMÁs Y VALIENTE, Francisco. Manual de Historia del Derecho español. Madrid, Tecnos, 2007. 